\title{
RARE SYNCHRONOUS PRIMARY CANCER IN GENITAL TRACT OF MIDDLE AGED FEMALE: SYNCHRONOUS PRIMARY ENDOMETRIAL ADENOCARCINOMA AND SEROUS PAPILLARY CYSTADENOCARCINOMA OF OVARY.
}

1. MBBS, M.Phil (Morbid Anatomy and Histopathology), DCP

Associate Professor Pathology Multan Medical \& Dental College, Multan.

2. MBBS

Resident Histopathology

Shaukat Khanum Memorial Cance Hospital \&

Research Centre, Lahore.

3. MD Pathologist

Morristown, Overlook and Newton Medical Centers

Atlantic Consolidated Laboratory

100 The American Road, Morris

Plains, NJ 07950

Correspondence Address:

Dr. Afra Samad

Postal address: House No.68. Street

No. 2

Mehrban Colony. Near MDA Chowk.

Multan.

afrasamad@yahoo.com

Article received on:

23/02/2019

Accepted for publication:

25/06/2019
Afra Samad', Madiha Syed², Arbaz Samad ${ }^{3}$

ABSTRACT: Synchronous cancers are defined as two or more histologically distinct malignancies arising in the same site, following each other in a sequence of $<2$ months. Synchronous primary cancers are rare in general population and account for only $0.5-1.7 \%$ of gynaecological malignancies..$^{1,2}$ It is important to distinguish synchronous primary tumors from metastatic malignancies. ${ }^{3}$ Case Report: We report a case of 55 years old female with history of pain in abdomen for the last one year. Surgical intervention was planned after complete work up. Hysterectomy with bilateral salpingo-oophorectomy and omentectomy was done. Histopathological examination reported the presence of synchronous endometrial adenocarcinoma well differentiated and malignant ovarian tumor low grade serous papillary cystadenocarcinoma. Conclusion: Though a rare presentation synchronous primary endometrial and ovarian cancers, usually identified at early stage and have a good prognosis.

Key words: Adjuvant Therapy, Endometrial Cancer, Ovarian Cancer, Synchronous Cancer.

Article Citation: Samad A, Syed M, Samad A. Rare synchronous primary cancer in genital tract of middle aged female: Synchronous primary endometrial adenocarcinoma and serous papillary cystadenocarcinoma of ovary. Professional Med J 2020; 27(2):437-441.

DOI: 10.29309/TPMJ/2020.27.2.3313

\section{INTRODUCTION}

This case highlights rare presentation of gynecological malignancy i.e synchronous primary endometrial adenocarcinoma well differentiated and low grade serous papillary cystadenocarcinoma. The age of onset ranges from 30 to 70 years.

It is important to distinguish between synchronous primary cancer and metastasis. In our literature search we found that patients diagnosed with synchronous primary cancers have a better overall prognosis compared to single primary cancer. ${ }^{4}$

\section{Case Report}

A 55 years old female presented with history of abdominal pain for the last one year. Her surgery was planned after complete work up. Hysterectomy with bilateral salpingooophorectomy and omentectomy was done. Specimen sent for histopathological examination.
On gross examination endometrial cavity showed a grayish white tumor measuring $3.0 \times 2.5 \times 0.8 \mathrm{~cm} \&$ left ovary showed a cyst measuring $5.0 \times 2.5 \times 0.5 \mathrm{~cm}$. Inner lining of cyst was grayish white smooth with wall thickness of $0.5 \mathrm{~cm}$.

Microscopic examination revealed histological features suggestive of endometrial adenocarcinoma well differentiated. The tumor infiltrated the superficial myometrium.

Section from left ovarian cyst showed tumor comprising of columns and aggregates of papillary structures lined by moderately pleomorphic epithelial cells.

The histological features are suggestive of low grade serous papillary cystadenocarcinoma of left ovary. Right ovary showed no tumour infiltration. Sections of omentum showed evidence of metastatic carcinoma. 


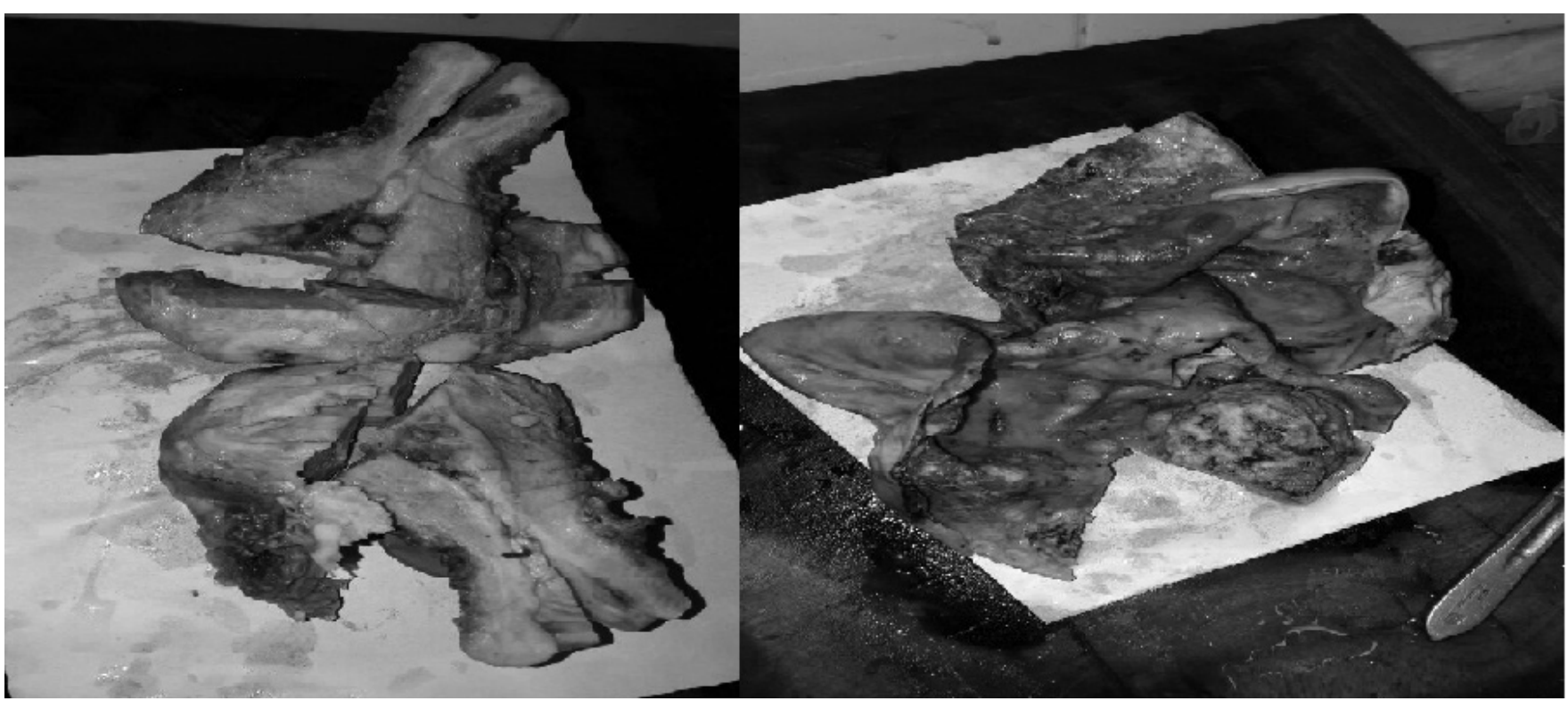

Figure-1. Gross appearance of the specimen of the case.

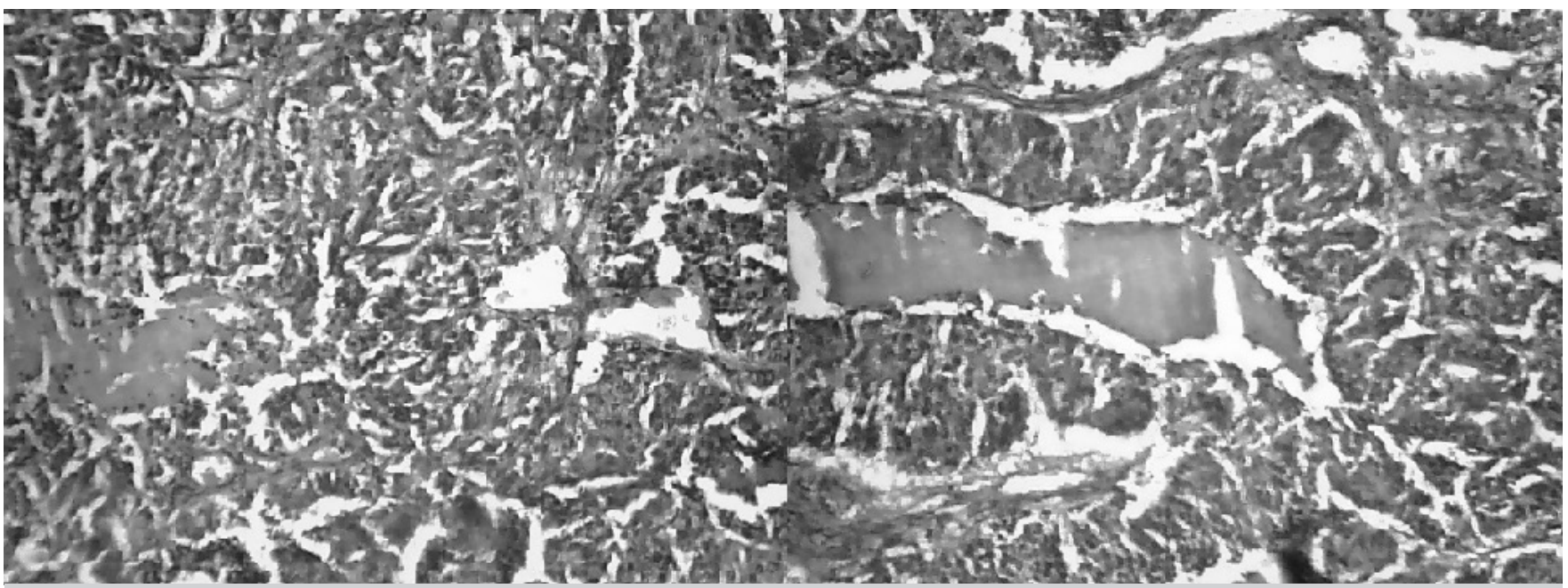

Figure-2. Low and high power view of microscopic appearance of endometrial adenocarcinoma well differentiated.

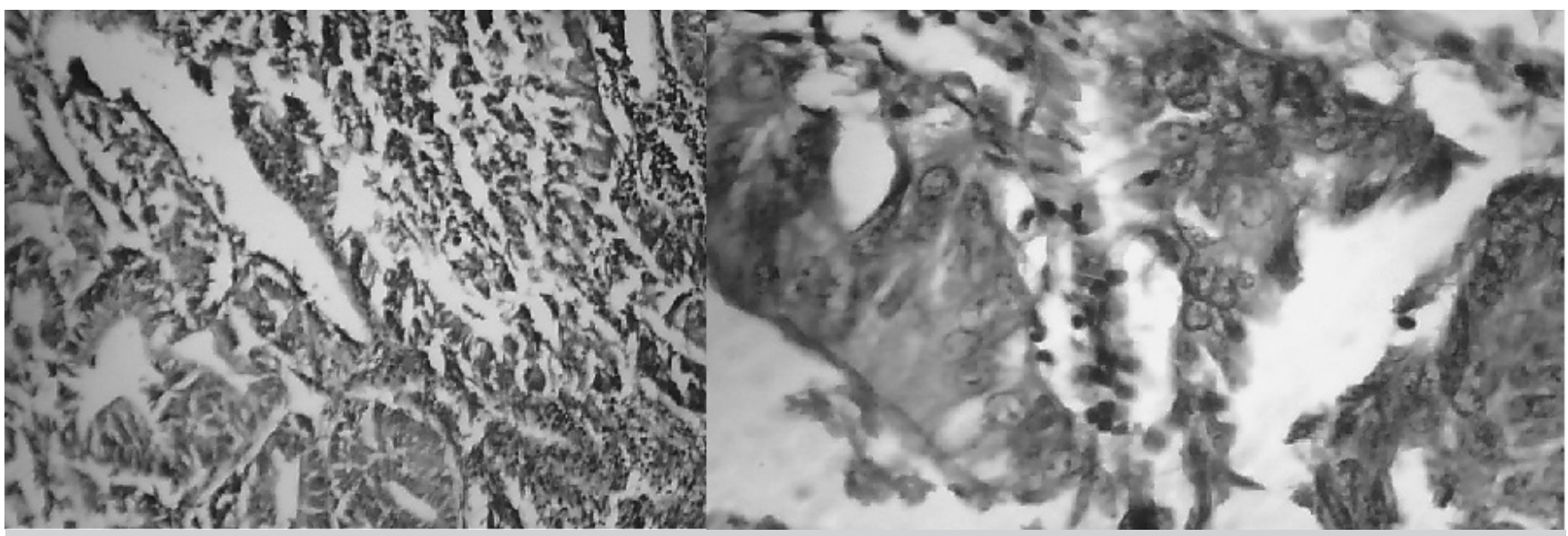

Figure-3. Microscopic appearance of serous cyst adenocarcinoma of ovary 


\section{DISCUSSION}

Synchronous cancers are defined as two or more histologically distinct malignancies arising at the same site following each other in a sequence of $<2$ months. Age group for synchronous primary endometrial and ovarian cancers ranges between 30-70 years. The median age at the time of diagnosis is being 50 years. Patients commonly present with the complaints of abdominal mass, abdominal pain and abdominal fullness ${ }^{3,5,6}$ The cause of synchronous primary endometrial and ovarian cancers is not exactly known. ${ }^{4,7}$ The theory of secondary mullerian system explains the development of synchronous primary cancer in female genital tract. This theory explains that epithelia of upper female genital tract respond to carcinogenic stimulus as a single morphological unit because of common embryologic origin., ${ }^{7,8}$ Perhaps synchronous primary cancers in the female genital tract occur due to shared hormone receptor. ${ }^{2,5,8}$ Other possibilities include fragile genome and prior genetic damage that may also lead to development of synchronous primary endometrial and ovarian cancers. ${ }^{9,10}$ Synchronous primary malignancies of female genital tract are a rare event. In order to distinguish between metastatic disease and independently existing primary tumor Young and Scully proposed criteria. $^{3}$

1: Histological dissimilarity of tumors.

2: No or only superficial myometrial invasion of endometrial tumor.

3: No vascular space invasion of endometrial tumor.

4: Atypical endometrial hyperplasia additionally present.

5: Absence of other evidence of spread of endometrial tumor.

6: Ovarian tumor unilateral (80-90\%) cases.

7: Ovarian tumors located mainly in parenchyma.

8: No vascular space invasion, surface implants, or pre-dominant hilar location in the ovary.

9: Absence of other evidence of spread of ovarian tumor.

10: Ovary endometriosis present.

11: Different ploidy of DNA indices, if aneuploid of the tumors.

12: Dissimilar molecular genetics or karyotypic abnormalities in the tumors.

Treatment of choice for synchronous primary endometrial and ovarian cancer is surgical staging. ${ }^{1,2,4,11-18}$ Systematic surgical staging includes total abdominal hysterectomy with unilateral salpingo-oophorectomy, total omentectomy, appendectomy, pelvic and paraaortic lymphadenectomy, complete resection of all disease, biopsy of any suspected lesion and pelvic washings. Pelvic and para-aortic lymphadenectomy plays a key role in surgical staging in patients with synchronous primary endometrial and ovarian cancers. ${ }^{1,2,17,18}$ It has diagnostic therapeutic and prognostic value. It helps in determining the extent of disease. Stage III disease can only be identified by paraaortic lymphadenectomy. ${ }^{1,2,17,18}$ Appropriate surgical staging facilitates targeted therapy that maximizes survival and minimizes morbidity of over treatment and effects of under treatment. ${ }^{1,2,19}$ Therapeutic approach plays are important role in determining stage related post-op adjuvant therapy. ${ }^{1,2,15,1}$ The decision of post-op adjuvant treatment should be individualized according to the risk of relapse of each primary cancer especially in patients with advanced stage disease, unfavorable histologic types and high grade disease, require post-op adjuvant therapy tailored to both tumors. ${ }^{2,20,21}$ Post-op adjuvant treatment includes post-op adjuvant radiotherapy and post-op adjuvant chemotherapy. Postop adjuvant radiotherapy includes ext. pelvic radiotherapy or brachytherapy. It is appropriate treatment for high risk endometrial cancer. ${ }^{1,2,15,16}$ Post-op adjuvant chemotherapy is the appropriate treatment for advanced stage primary endometrial ovarian cancers. ${ }^{1,2,21}$ Most effective chemotherapeutic agents include anthracyclins and platinum compounds. ${ }^{12}$ Prognostic factors for synchronous primary endometrial and ovarian cancers are age, stage of ovarian cancer, grade of endometrial cancer and adjuvant treatment. ${ }^{22,23}$ Patients with primary endometrial and ovarian cancers have overall survival of 5 years. Patients with synchronous primary endometrial and ovarian cancers have better overall prognosis. The better overall prognosis in due to detection of disease at an early stage and low grade 
disease. $^{1,2,4,14}$

\section{CONCLUSION}

This case highlights rare presentation of gynecological malignancies synchronous primary endometrial adenocarcinoma and ovarian serous papillary cystadenocarcinoma. Secondary mullerian system explains pathogenesis of disease. The synchronous cancers are usually diagnosed at an earlier stage have lower grading and prognosis is better when compared to a single advanced cancer. It is important to distinguish synchronous primary cancer and metastasis. Surgical staging and depending upon the risk of recurrence post operative adjuvant therapy are treatment options.

Copyright@ 25 June, 2019.

\section{REFERENCES}

1. Androutsopoulos G, Decavalas G. Synchronous primary endometrial \& ovarian cancers. J Community Med Health Edu 3; 2013: 120.

2. Androutsopoulos G, Decavalas G. Synchronous primary endometrial \& ovarian cancers; Pathogenesis, treatment and Prognosis. Int $\mathrm{J}$ cliu Ther diagnosis 2014: 601.

3. Young RH, Scully RE. Metastatic tumour of ovary. In kurman RJ, editor. Blaustein's gynaecological pathology of female genital tract $6^{\text {th }}$ Edition. Springer; New York 2002: 987-990.

4. Ayhan A, Yalcin OT, Tuncer ZS. Gurgan T, Kucukali T. Synchronous primary malignancies of female genital tract. Eur J Obsted Gynecol Reprod Biol 1992; 45: 6366.

5. Esev S, Gulhan I, Ozdemir R, Dicle N, Hanhan M, et al. Synchronous primary cancers of female reproductive tract. Asian pac J Cancers Prev 2011; 12: 857-859.

6. Soliman DT, Sloncovitz BM, Broaddus, RR, Sunce, Oh JC, et al. Synchronous primary cancers of endometrium \& ovary a single institution review of 84 cases. Gynecol Oncol 2004; 94: 456-462.

7. Rodolakis A, Thomakos N, Akrivos N, Sotiropoulour M, Loaunidis I, et al. Clinicopathological insight of simultaueously detected primary endometrial \& ovarian carcinomas. Arch Gynecol obestet $2012 ; 285$ : 817-821.
8. Chiang YC, Cheu CA, Huang CY, Hsieh CY, Cheng WF. Synchronous primary cancer of endometrium and ovary. Int J Gynecol Cancer 2008; 18: 15-164.

9. Kaueki E, Oda Y, Ohishi Y, et al. Frequent microsatellite instability in synchronous ovarian and endometrial adenocarcinomas and its usefulness for differential diagnosis. Hum Pathol 2004; 35: 1484-1493.

10. Ricei $R$, Komminoth $P$, Bannwart $F$, et al. PTEN as a molecular marker to distinguish metastatic from primary synchronous endometrial carcinomas of ovary and uterus. Diagon Mol Pathol 2003; 12: 71-78.

11. Thong SY, Lee YS, Park JS, Bae SN, Lee JM, et al. Clinical analysis of synchronous primary neoplasms of female Reproductive tract. Eur J Obstet Gynecol Reprod Biol 2008; 136: 78-82.

12 .Liu Ym LiJ, Jiu H, Luy, Lux. Clinicopathological characteristics of patients with synchronous primary endometrial and ovarian cancers. A review of 43 cases. Oncol Lett 2013; 5: 267-270.

13. Singorelli M, Frusciok, Lissioni AA, Pirovammoc, perego $P$, et al. Synchronous early stage endometrial and ovarian cancers. Int J Gyncol Obsted 2008; 102: 34-38.

14. Andeoutsopoulos G, Adonakis G, Tsauraudas A, Andonopoulos A, Decavalas G. Systemic Sclerosis and multiple cancers of female gential tract. Prolonged survival following current treatment strategies. Case Rep Rheumatol 2011; 392068.

15. Androutsopoulos G, Decavalas G. Management of endometrial cancers. Int J Trans Commun Med 2013; 1: 101.

16. Androutsopoulos G. Current treatment options in patients with endometrial cancer. J community Med Health Edu 2012; 2: 13.

17. Part J. FIGO comittee on Gyncologic oncology staging classificantion for cancer of the ovary, fallopian tube, and peritoneum. Int J Gynecol Obstet 2014; 124: 1-5.

18. Pecorelli $S$ Revised FIGO staging for carcinoma of vulva, cervix and endometrium. Int J Gynecol obstet 105; 103-104.

19. American college of obstetrician and Gynecologists. ACOG practice bulletin, clinical management guidelines for obstetrician gynecologists Nuclear 65, Management of endometrial cancer 2005; 106 : 413-425.

20. Ma S, Zhang H, Sun Y, Wu L. Synchronous primary cancers of endometrium and ovary review of 43 cases Chinese. German J cliu Onco 2009; 8: 95-99. 
21. Heitz F, Amaut F, Fo topoulon C, Battista MJ, Wimberger $P$, et al. Synchronous endometrial and ovarian canceran- international multi-center case-control study. Int J Gynecol cancer 2014; 24: 54-60.

22. Lim Y K, Padma R, Foo L, Clia Y N, Yaun P, et al. Survival outcome of women with Synchronous cancers of endometrium and ovary. A 10 year retrospective cohort study. J Gynecol oncol 2011; 22: 239-243.
23. Song T, Seong SJ, Bae DS, Kim JH, Suh DH, et al. Prognostic factors in women with Synchronous endometrial and ovarian cancers. Int J Gynecol Cancer 2014; 24: 520-527.

\begin{tabular}{|c|l|l|l|}
\hline \multicolumn{3}{|c|}{ AUTHORSHIP AND CONTRIBUTION DECLARATION } \\
\hline Sr. \# & Author(s) Full Name & Contribution to the paper & Author(s) Signature \\
\hline 1 & Afra Samad & 1st Author & $\begin{array}{r}\text { Afra.Samad. } \\
\text { Madihasyeed. }\end{array}$ \\
\hline 2 & Madiha Syed & 2nd Author & Arbazs \\
\hline 3 & Arbaz Samad & 3rd Author & \\
\hline
\end{tabular}

